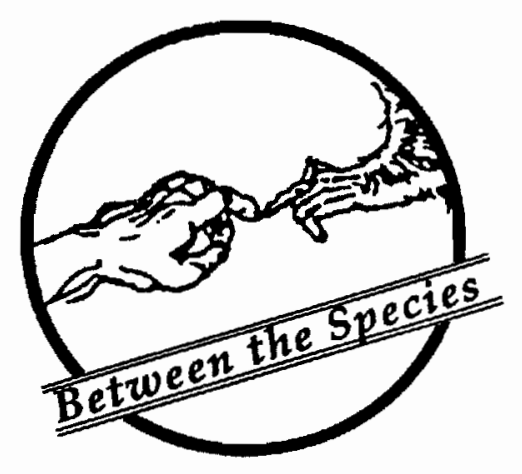

\title{
THE "VALUES" OF SENTIENT BEINGS
}

\section{Dr. Michael W. Fox \\ Center for Respect of Life and Environment \\ Washington, D.C.}

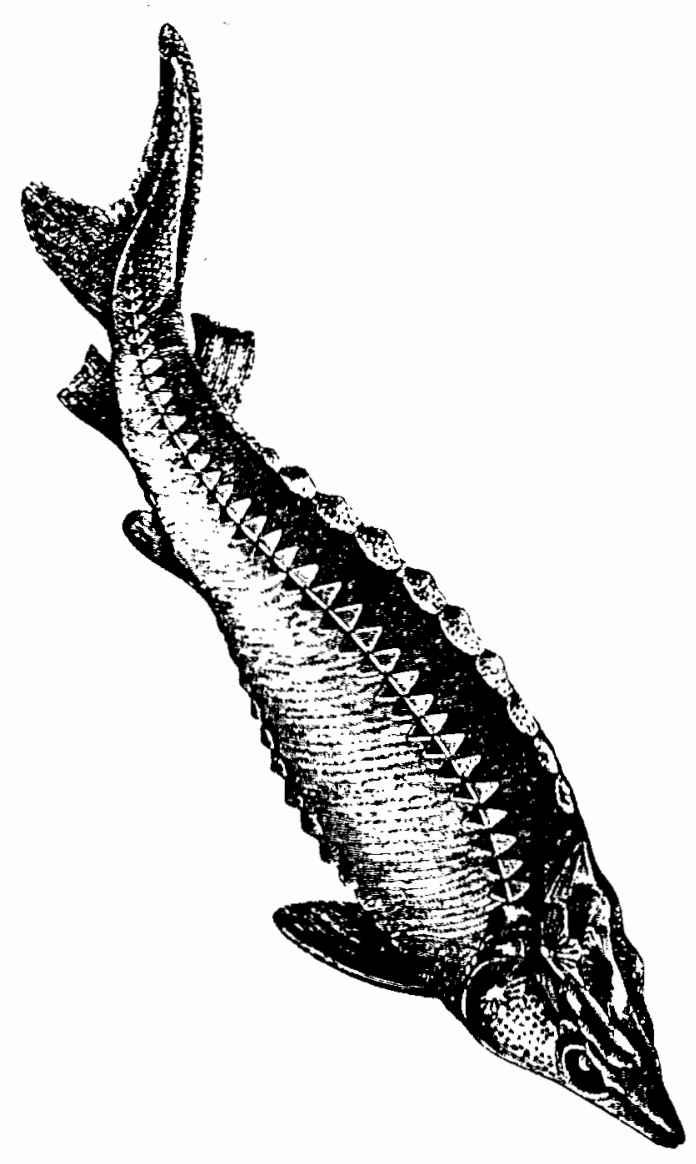

M any animal rights philosophers have emphasized the importance of recognition of the inherent or intrinsic value of animals in encouraging a deeper respect for non-human life. The intrinsic value of animals is contrasted with the perceived extrinsic value from the point of view of human utility. Intrinsic value is regarded by animal rightists as taking precedence over an animal's extrinsic value, because animals are ends in themselves rather than the means to satisfy purely human ends.

However, we should not dismiss in our thinking the fact that animals and other existences are not purely ends in themselves. The deer has inherent value and a life of its own but is a means whereby the needs of predator species such as the wolf and tiger are satisfied.

While this is a fact of Nature, it is what I call a naturalistic fallacy to rationalize from this fact that since animals prey upon and kill each other there can be nothing wrong with humans doing likewise. Predator species are always few in number. But six

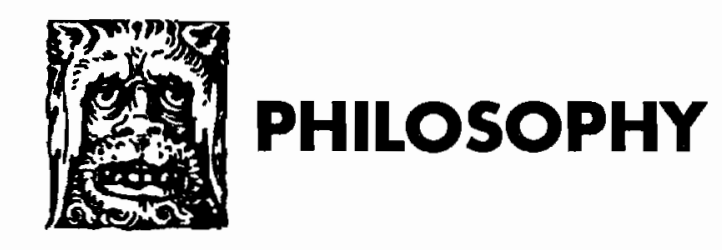


billion animals the size of Homo sapiens on this small planet is a biological aberration with devastating ecological consequences when they behave as predators.

In recognizing the extrinsic value of animals and other living things in their contribution to the harmony, beauty and diversity of the biotic community, the animal rightist moves conceptually toward a more holistic, ecological view. This has been lacking too long in the movement, as has respect for the inherent value of animals as individuals by the environmental and conservation movements.

Some philosophers, reflecting a fairly prevalent social consensus, believe that domesticated animals that were "created" by man for specific human use have less inherent value than wild animals. This is also fallacious I believe, because it is indicative of an anthropocentric attitude toward non-human life that embraces the "naturalistic fallacy" alluded to earlier.

It may be reasoned that a being that is more intelligent and self-aware than another has greater inherent value. This again could be based upon anthropocentrism and have racist and speciesist consequences. Furthermore, in focusing upon inherent value to the exclusion of extrinsic value (or vice versa), the natural paradox between the two is not appreciated. This is that organisms, such as soil bacteria and fungi, which, from an anthropocentric perspective have less inherent value than say a more sentient and sapient wolf or human being, actually have a greater extrinsic or instrumental value in terms of their contribution to the integrity of the biotic community. Nothing will grow in sterilized soil devoid of microorganisms.

Another considerable aspect especially of nonsentient (or more correctly pre-sentient) existences is their potential. The inherent potential of an individual human being is relatively finite compared to a plant or bacterium that can multiply asexually and clone itself. The inherent potential of rocks, embodying trace minerals, and of water, that are the basic elements incorporated into all life forms, is infinite.

Thus when contemplating that which St. Francis called "sister" water, we become aware of an existence that is devoid of consciousness, of sentience and of intrinsic value in terms of having a life of its own. From that limited perspective, sister water is 'inferior' to Homo sapiens. But by virtue of her inherent potential, she is clearly superior. And in terms of her extrinsic value to all life, she embodies those qualities that we equate with the saintly virtue of selfless giving to all life. When we begin to perceive other existences, be it from the sacramental panentheistic perspective of St. Francis or from an instrumental yet holistic view of intrinsic/extrinsic value and potential, the notion of human "superiority" is shattered.

In conclusion, it is important I believe to consider both the intrinsic and extrinsic value of all existences in arguing the case for animal rights and conservation. While "rights" language has its limitations and some prefer to speak in terms of human obligations and duties, a greater appreciation of the extrinsic value of natural organisms - of their place and 'role' in Nature, - will bring an ecological/environmental perspective to the inherent value-oriented approach of the animal rights movement and philosophy. And as a final thought, we might ask of the presumed most sapient and sentient Earth species with the acclaimed greatest inherent value, what extrinsic value it has in terms of contributing to the integrity, stability and beauty of the biotic community. Had we the simplicity of bacteria, the humility of the deer and the wisdom of the wolf, we might be of more value to the natural world.

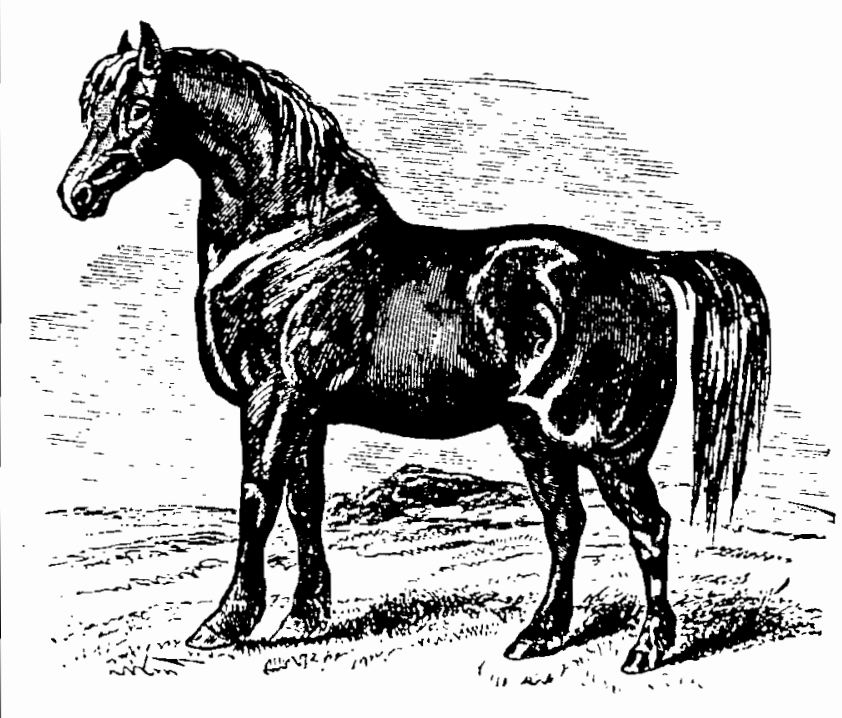

